\title{
Investigación
}

\section{Ética digital en}

una sociedad

transformada

DOI: 10.29236/sistemas.n153a4

Investigación basada en una única pregunta realizada a los profesionales de la base de datos de la Asociación Colombiana de Ingenieros de Sistemas -ACIS-.

\section{Manuel Dávila Sguerra}

En este número de la revista Sistemas sobre ética digital hemos consultado a los profesionales que conforman nuestra base de datos mediante la pregunta: "Considerando que la tecnología transforma a la sociedad, en su opinión ¿qué no es ético en la aplicación de las tecnologías emergentes?".
Consulta que generó una serie de respuestas con libertad de extensión para tabularla y proceder a sistematizar los resultados.

\section{Metodología}

La encuesta permitió que las respuestas fueran hechas con libertad de extensión del texto. Es decir 
que, en un párrafo pueden existir varias opiniones consideradas respuestas diferentes. Por tal razón, en el listado de respuestas clasificadas se encontrarán párrafos repetidos, pero con varias clasificaciones, una por opinión.
El análisis se realizó sobre un total de 102 opiniones presentadas en este documento. Se asignó una palabra representativa a cada opinión con el propósito de agrupar conceptos y graficar los resultados bajo diferentes categorías.

\section{Listado de respuestas clasificadas}

\begin{tabular}{|l|l|}
\hline Respuestas a la pregunta: & Clasificación \\
\hline $\begin{array}{l}\text { "Considerando que la tecnología transforma a } \\
\text { la sociedad, en su opinión, ¿qué no es ético en } \\
\text { la aplicación de las tecnologías emergentes?" }\end{array}$ & \\
\hline $\begin{array}{l}\text { Espiar a los demás, difamar a otros, mentir, utilizar } \\
\text { la tecnología para realizar trampas o hacer daño a } \\
\text { los demás., Robar información, instalar o enviar } \\
\text { software malicioso, secuestrar información. Utili- } \\
\text { zar la tecnología para lucrarse de forma ilícita, ya } \\
\text { sea con menores, adultos o de cualquier otra ma- } \\
\text { nera. Inducir a otros a hacer cosas por moda. }\end{array}$ & \\
\hline \begin{tabular}{l} 
El uso abusivo de la información personal. \\
\hline $\begin{array}{l}\text { El uso de la tecnología en la generación falsa de } \\
\text { contenidos "deepfakes", el acoso y la automatiza- } \\
\text { ción de las armas. }\end{array}$
\end{tabular} & Acosar \\
\hline $\begin{array}{l}\text { Pasar por encima de los derechos y deberes. } \\
\text { mercializador de tecnología. Y cuando alguna de } \\
\text { tre el productor de tecnología y el consumidor/co- } \\
\text { las partes, o un tercero, se aproveche en }\end{array}$ & Anarquía \\
\hline $\begin{array}{l}\text { La manipulación tergiversada de los datos para } \\
\text { conseguir propósitos económicos, acceder a infor- } \\
\text { mación privilegiada sin permiso del dueño de la } \\
\text { misma. }\end{array}$ & Aprovechar \\
\hline $\begin{array}{l}\text { Todo lo que atente contra los valores personales, } \\
\text { pamiliares y de la sociedad. Cuando no queda ex- }\end{array}$ & Aprovechar \\
\hline
\end{tabular}




\begin{tabular}{|l|l|}
\hline menoscabo de personas. & \\
\hline $\begin{array}{l}\text { Aprovecharse de la gente que no entiende de tec- } \\
\text { nología y hacerle invertir en cosas que no necesita. }\end{array}$ & Aprovechar \\
\hline $\begin{array}{l}\text { Utilizar indebidamente información personal o con- } \\
\text { fidencial. }\end{array}$ & Aprovechar \\
\hline $\begin{array}{l}\text { El uso de la tecnología en la generación falsa de } \\
\text { contenidos "deepfakes", el acoso y la automatiza- } \\
\text { ción de las armas. }\end{array}$ & Armas \\
\hline $\begin{array}{l}\text { Especialmente la invasión de la privacidad. A tra- } \\
\text { vés del envío de información de publicidad y meca- } \\
\text { nismos o trucos que incitan o provocan por error la } \\
\text { adquisición de productos o el ingreso a espacios } \\
\text { no deseados o no esperados. Las personas somos } \\
\text { "atropellados" constante y descaradamente en to- } \\
\text { dos los "espacios virtuales" a los cuales accede- } \\
\text { mos (Ejemplo: buzón de correo, páginas, portales, } \\
\text { aplicaciones, etc.). }\end{array}$ & \\
\hline $\begin{array}{l}\text { Considero que no es ético el hecho de utilizar infor- } \\
\text { mación que no ha sido autorizada para beneficios } \\
\text { comerciales o de investigaciones. De la misma } \\
\text { manera, no es correcto que se usen artificios enga- } \\
\text { ñosos para recolectar información y se manipule la } \\
\text { opinión o el comportamiento de los ciudadanos. }\end{array}$ & Autorizar \\
\hline $\begin{array}{l}\text { Que no se filtre la información y se permita compar- } \\
\text { tir contenido basura. }\end{array}$ & Basura \\
\hline $\begin{array}{l}\text { En Aplicación de las Tecnologías Emergentes, no } \\
\text { en esta acción. } \\
\text { mionanotico, experimentos no convencionales en la } \\
\text { mano, y de las futuras generaciones. }\end{array}$ & Bioética \\
\hline $\begin{array}{l}\text { Los propietarios de una aplicación tecnológica rea- } \\
\text { lianzas internas - privadas sin dar a conocer }\end{array}$ & Carteles \\
\hline
\end{tabular}




\begin{tabular}{|l|l|}
\hline $\begin{array}{l}\text { Todo lo que haga público información confidencial } \\
\text { o reservada de personas o instituciones. }\end{array}$ & Confidencialidad \\
\hline $\begin{array}{l}\text { Crear información errada o sin validar si es correc- } \\
\text { ta o no y aprovechar las facilidades de envíos ma- } \\
\text { sivos por cualquier medio de tantos que hay por } \\
\text { ejemplo en redes sociales o WhatsApp para con- } \\
\text { fundir a la gente. }\end{array}$ & Confundir \\
\hline \begin{tabular}{l} 
Solamente consumir tecnología sin desarrollar. \\
\hline $\begin{array}{l}\text { Uso inadecuado o no controlado de estas tecnolo- } \\
\text { gías. }\end{array}$
\end{tabular} & Consumir \\
\hline $\begin{array}{l}\text { Utilizar la información personal para promover la } \\
\text { disminución de derechos y libertades de los indivi- } \\
\text { duos. }\end{array}$ & Controlar \\
\hline $\begin{array}{l}\text { Utilizar la tecnología para hacer daño a las perso- } \\
\text { nas en cualquier aspecto. }\end{array}$ & Dañar \\
\hline $\begin{array}{l}\text { Dañar a otros por medio de cualquiera de los deli- } \\
\text { tos informáticos, aprovecharse del desconoci- } \\
\text { miento de algunos, violentar la privacidad. Lucrase } \\
\text { ilícitamente. }\end{array}$ & Dañar \\
\hline $\begin{array}{l}\text { No es ético que se utilicen estas tecnologías para } \\
\text { causarle daño a la humanidad y en consecuencia } \\
\text { generar un efecto negativo en la transformación de } \\
\text { la sociedad la cual no quiere que se repita el uso de } \\
\text { la tecnología nuclear para destrucción masiva me- } \\
\text { diante bombas nucleares. La sociedad espera que } \\
\text { las tecnologías se utilicen para el avance honesto, } \\
\text { íntegro, correcto, justo y honrado de la humanidad. }\end{array}$ & \\
\hline $\begin{array}{l}\text { Dañar a otros por medio de cualquiera de los deli- } \\
\text { miento de algunos, violentar la privacidad. Lucrase } \\
\text { ilícitamente. }\end{array}$ & Delinquir \\
\hline $\begin{array}{l}\text { Utilizarlas para cometer Delinquir o afectar la hon- } \\
\text { ra persona. }\end{array}$ & Delinquir \\
\hline
\end{tabular}




\begin{tabular}{|c|c|}
\hline Desarrollar para cometer Delinquir. & Delinquir \\
\hline $\begin{array}{l}\text { Utilizar las tecnologías para excluir, desarrollar o } \\
\text { aplicarlas sin considerar efectos colaterales o de } \\
\text { impacto al ambiente (social, cultural, económico, } \\
\text { político, ecológico), una aplicación que invisibilice } \\
\text { o denigre al ser humano. }\end{array}$ & Denigrar \\
\hline $\begin{array}{l}\text { Las mismas faltas a la ética que en cualquier cam- } \\
\text { po: violación de derechos, fraude, transgredir la } \\
\text { privacidad de los individuos, cualquier uso de tec- } \\
\text { nologías emergentes que tenga implícito irrespeto, } \\
\text { violación de derechos, que atente contra la vida de } \\
\text { personas plantas o animales...contra el planeta. }\end{array}$ & Derechos \\
\hline $\begin{array}{l}\text { Utilizarlas para cometer delitos o afectar la honra } \\
\text { de una persona. }\end{array}$ & Deshonrar \\
\hline $\begin{array}{l}\text { Implementar tecnologías sin pensar en acciones } \\
\text { que permitan mitigar los efectos negativos de di- } \\
\text { chas implementaciones, por ejemplo, el aumento } \\
\text { de la desigualdad en términos sociales, laborales y } \\
\text { económicos que podrían generar implementacio- } \\
\text { nes masivas de Al en países subdesarrollados. }\end{array}$ & Desigualdad \\
\hline $\begin{array}{l}\text { El ser humano se reemplace y se desplace por la } \\
\text { tecnología y se pierda el sentido de la humanidad } \\
\text { en el mundo, nos volvemos esclavos de la tecnolo- } \\
\text { gía. Sin embargo, es necesario en algunos ámbi- } \\
\text { tos como la salud. }\end{array}$ & Desplazar \\
\hline $\begin{array}{l}\text { El desplazamiento de las personas por maquinas, } \\
\text { éstas harán el trabajo de varias personas en menor } \\
\text { tiempo y con menos grado de error. cabe la pena } \\
\text { aclarar que estamos en una época en la cual la tec- } \\
\text { nología está al servicio del hombre para prestarle } \\
\text { beneficios y ayudas en su diario vivir. }\end{array}$ & Desplazar \\
\hline $\begin{array}{l}\text { El uso de las tecnologías emergentes para generar } \\
\text { discriminación basada en preferencias políticas y } \\
\text { religiosas. }\end{array}$ & Discriminar \\
\hline Implementar tecnologías sin pensar en acciones & Discriminar \\
\hline
\end{tabular}




\begin{tabular}{|l|l|}
\hline $\begin{array}{l}\text { que permitan mitigar los efectos negativos de di- } \\
\text { chas implementaciones, por ejemplo, el aumento } \\
\text { de la desigualdad en términos sociales, laborales y } \\
\text { económicos que podrían generar implementacio- } \\
\text { nes masivas de Al en países subdesarrollados. }\end{array}$ & \\
\hline $\begin{array}{l}\text { La no protección de la personas y su información y } \\
\text { la publicación indiscriminada de contenidos. }\end{array}$ & Discriminar \\
\hline $\begin{array}{l}\text { Hacer creer (con mercadotecnia, por ejemplo) que } \\
\text { es más poderosa que el ser humano. }\end{array}$ & Engañar \\
\hline $\begin{array}{l}\text { Considero que no es ético el hecho de utilizar infor- } \\
\text { mación que no ha sido autorizada para beneficios } \\
\text { comerciales o de investigaciones. De la misma } \\
\text { manera, no es correcto que se usen artificios enga- }\end{array}$ & Engañar \\
$\begin{array}{l}\text { ñosos para recolectar información y se manipule la } \\
\text { opinión o el comportamiento de los ciudadanos. }\end{array}$ & \\
\hline $\begin{array}{l}\text { Colocar a la tecnología por encima del negocio } \\
\text { mismo. }\end{array}$ & Equilibrar \\
\hline $\begin{array}{l}\text { El ser humano se reemplace y se desplace por la } \\
\text { tecnología y se pierda el sentido de la humanidad } \\
\text { en el mundo, nos volvemos esclavos de la tecnolo- } \\
\text { gía. Sin embargo, es necesario en algunos ámbi- } \\
\text { tos como la salud. }\end{array}$ & \\
\hline $\begin{array}{l}\text { No divulgar toda aquella información que beneficia } \\
\text { directamente a toda la sociedad aunque contenga } \\
\text { elementos de protección de autoría o sea estable- } \\
\text { cida en términos muy restrictivos. }\end{array}$ & Esconder \\
\hline $\begin{array}{l}\text { zar la tecnología para lucrarse de forma ilícita, ya } \\
\text { nera. Inducir a otros a hacer cosas por moda. } \\
\text { la tecnología para realizar trampas o hacer daño a }\end{array}$ & \\
\hline
\end{tabular}




\begin{tabular}{|l|l|}
\hline $\begin{array}{l}\text { La ética es única y no debe cambiar use o no Tec- } \\
\text { nología. }\end{array}$ & Ética universal \\
\hline $\begin{array}{l}\text { Usar la tecnología como mecanismo para excluir } \\
\text { comunidades de bajos recursos. }\end{array}$ & Excluir \\
\hline $\begin{array}{l}\text { El desarrollo de plataformas de algún modo ha caí- } \\
\text { do en la explotación laboral, para algunos casos es } \\
\text { una oportunidad de captar ingresos adicionales, } \\
\text { pero en otros se ha convertido en la única fuente de } \\
\text { ingresos sin garantías ni beneficios. }\end{array}$ & \\
\hline $\begin{array}{l}\text { Publicar noticias falsas o noticias que promuevan } \\
\text { odio. }\end{array}$ & Falsear \\
\hline $\begin{array}{l}\text { Amí me preocupan en particular los usos conjuga- } \\
\text { dos de varias tecnologías para fines nocivos. Un } \\
\text { ejemplo es el uso de inteligencia artificial para ha- } \\
\text { cer videos que hacen lip sync falsos, y que pudie- } \\
\text { ran compartirse en redes sociales para difundir } \\
\text { masivamente noticias falsas. }\end{array}$ & \\
\hline $\begin{array}{l}\text { El uso de la tecnología en la generación falsa de } \\
\text { contenidos "deepfakes", el acoso y la automatiza- } \\
\text { ción de las armas. }\end{array}$ & Falsear \\
\hline $\begin{array}{l}\text { Utilizarlas en contra de la libertad y felicidad del in- } \\
\text { dividuo. }\end{array}$ & Felicidad \\
\hline $\begin{array}{l}\text { Las mismas faltas a la ética que en cualquier cam- } \\
\text { po: violación de derechos, fraude, transgredir la } \\
\text { privacidad de los individuos, cualquier uso de tec- } \\
\text { nologías emergentes que tenga implícito irrespeto, } \\
\text { violación de derechos, que atente contra la vida de } \\
\text { personas prabado hoy porade } \\
\text { las conversaciones que se tienen, es importante }\end{array}$ & \\
\hline
\end{tabular}




\begin{tabular}{|l|l|}
\hline $\begin{array}{l}\text { Hacer uso de la IA para romper los esquemas de } \\
\text { protección en la identificación de un humano y una } \\
\text { máquina. }\end{array}$ & Identificar \\
\hline $\begin{array}{l}\text { El aprovechamiento por parte de un reducido sec- } \\
\text { tor de la población y la ausencia de responsabili- } \\
\text { dad social en su uso. }\end{array}$ & Inequidad \\
\hline Excluir minorías argumentando mayorías. & Inequidad \\
\hline La seguridad de la información. & Inseguridad \\
\hline $\begin{array}{l}\text { La excesiva intromisión en los asuntos personales } \\
\text { y perdida de privacidad a que conlleva. }\end{array}$ & Intromisión \\
\hline $\begin{array}{l}\text { Las mismas faltas a la ética que en cualquier cam- } \\
\text { po: violación de derechos, fraude, transgredir la } \\
\text { privacidad de los individuos, cualquier uso de tec- } \\
\text { nologías emergentes que tenga implícito irrespeto, } \\
\text { violación de derechos, que atente contra la vida de } \\
\text { personas plantas o animales...contra el planeta. }\end{array}$ & \\
\hline $\begin{array}{l}\text { El aprovechamiento por parte de un reducido sec- } \\
\text { tor de la población y la ausencia de responsabili- } \\
\text { dad social en su uso. }\end{array}$ & Irresponsabilidad \\
\hline $\begin{array}{l}\text { Utilizar la IA para correlacionar mis redes sociales } \\
\text { para determinar si soy viable para un cargo o pues- } \\
\text { to de trabajo donde me esté postulando. }\end{array}$ & Laboral \\
\hline $\begin{array}{l}\text { Cualquier uso de la misma en contra de la libertad y } \\
\text { privacidad de las personas. }\end{array}$ & Libertad \\
\hline $\begin{array}{l}\text { Utilizarlas en contra de la libertad y felicidad del in- } \\
\text { dividuo. }\end{array}$ & Libertad \\
\hline $\begin{array}{l}\text { Dañar a otros por medio de cualquiera de los deli- } \\
\text { tos informáticos, aprovecharse del desconoci- } \\
\text { miento de algunos, violentar la privacidad. Lucrase } \\
\text { ilícitamente. }\end{array}$ & Lucrar \\
\hline
\end{tabular}




\begin{tabular}{|c|c|}
\hline $\begin{array}{l}\text { Lo que sucede hoy día: Utilización de la data de } \\
\text { nuestro comportamiento dentro de estas tecnolo- } \\
\text { gías para lograr de una u otra forma manipulación } \\
\text { para diversos fines. }\end{array}$ & Manipular \\
\hline $\begin{array}{l}\text { La manipulación de la información personal y de } \\
\text { los gustos y preferencias de las personas para be- } \\
\text { neficio de las compañías, sin previo conocimiento } \\
\text { por parte del propietario de los datos. }\end{array}$ & Manipular \\
\hline $\begin{array}{l}\text { Espiar a los demás, difamar a otros, mentir, utilizar } \\
\text { la tecnología para realizar trampas o hacer daño a } \\
\text { los demás., Robar información, instalar o enviar } \\
\text { software malicioso, secuestrar información. Utili- } \\
\text { zar la tecnología para lucrarse de forma ilícita, ya } \\
\text { sea con menores, adultos o de cualquier otra ma- } \\
\text { nera. Inducir a otros a hacer cosas por moda. }\end{array}$ & Mentir \\
\hline $\begin{array}{l}\text { La manipulación de la información personal y de } \\
\text { los gustos y preferencias de las personas para be- } \\
\text { neficio de las compañías, sin previo conocimiento } \\
\text { por parte del propietario de los datos. }\end{array}$ & Mercadeo \\
\hline $\begin{array}{l}\text { Espiar a los demás, difamar a otros, mentir, utilizar } \\
\text { la tecnología para realizar trampas o hacer daño a } \\
\text { los demás., Robar información, instalar o enviar } \\
\text { software malicioso, secuestrar información. Utili- } \\
\text { zar la tecnología para lucrarse de forma ilícita, ya } \\
\text { sea con menores, adultos o de cualquier otra ma- } \\
\text { nera. Inducir a otros a hacer cosas por moda. }\end{array}$ & Moda \\
\hline $\begin{array}{l}\text { El uso indiscriminado de fuentes de información } \\
\text { sin citarlas o manejando información que no ha si- } \\
\text { do verificada. }\end{array}$ & No validar \\
\hline $\begin{array}{l}\text { Crear información errada o sin validar si es correc- } \\
\text { ta o no y aprovechar las facilidades de envíos ma- } \\
\text { sivos por cualquier medio de tantos que hay por } \\
\text { ejemplo en redes sociales o WhatsApp para con- } \\
\text { fundir a la gente. }\end{array}$ & No validar \\
\hline $\begin{array}{l}\text { El uso irresponsable al emitir información sin con- } \\
\text { firmar y sin consulta de fuentes válidas. }\end{array}$ & No validar \\
\hline
\end{tabular}




\begin{tabular}{|c|c|}
\hline $\begin{array}{l}\text { Dejar códigos ocultos en las aplicaciones para ro- } \\
\text { bar datos. }\end{array}$ & Ocultar \\
\hline Datos abiertos. & Open Data \\
\hline $\begin{array}{l}\text { La intromisión en la privacidad para vender esta in- } \\
\text { formación a quienes tienen el poder de dirigir las } \\
\text { políticas de la sociedad. Esta es uno de los facto- } \\
\text { res que de manera ambivalente pueden empode- } \\
\text { rar una democracia más fuerte o debilitarla hasta } \\
\text { convertirla en una dictadura. }\end{array}$ & Política \\
\hline $\begin{array}{l}\text { Respetar la intimidad de las personas, trabajar da- } \\
\text { tos anonimizados. }\end{array}$ & Privacidad \\
\hline $\begin{array}{l}\text { La vulneración de la privacidad (confidencialidad) } \\
\text { de la información. }\end{array}$ & Privacidad \\
\hline $\begin{array}{l}\text { No es ético aprovechar la tecnología para vulnerar } \\
\text { los derechos y la privacidad de las personas. }\end{array}$ & Privacidad \\
\hline $\begin{array}{l}\text { Cualquier uso de la misma en contra de la libertad y } \\
\text { privacidad de las personas. }\end{array}$ & Privacidad \\
\hline $\begin{array}{l}\text { Dañar a otros por medio de cualquiera de los deli- } \\
\text { tos informáticos, aprovecharse del desconoci- } \\
\text { miento de algunos, violentar la privacidad. Lucrase } \\
\text { ilícitamente. }\end{array}$ & Privacidad \\
\hline $\begin{array}{l}\text { El seguimiento a las actividades cotidianas a tra- } \\
\text { vés de las redes sociales. No es claro y evidente } \\
\text { para la mayoría de los usuarios lo invasivo a la pri- } \\
\text { vacidad de estas aplicaciones. }\end{array}$ & Privacidad \\
\hline La violación de la privacidad. & Privacidad \\
\hline $\begin{array}{l}\text { Violación a la privacidad sin permiso del usuario. } \\
\text { Eso implica vender información de los usuarios sin } \\
\text { su consentimiento. }\end{array}$ & Privacidad \\
\hline $\begin{array}{l}\text { La excesiva intromisión en los asuntos personales } \\
\text { y perdida de privacidad a que conllevaLa invasión } \\
\text { a la privacidad. }\end{array}$ & Privacidad \\
\hline
\end{tabular}




\begin{tabular}{|l|l|}
\hline Analizar datos con información personal incluida. & Privacidad \\
\hline $\begin{array}{l}\text { Especialmente la invasión de la privacidad. A tra- } \\
\text { vés del envío de información de publicidad y meca- } \\
\text { nismos o trucos que incitan o provocan por error la } \\
\text { adquisición de productos o el ingreso a espacios } \\
\text { no deseados o no esperados. Las personas somos }\end{array}$ & \\
"atropellados" constante y descaradamente en to- \\
dos los "espacios virtuales" a los cuales accede- \\
mos (Ejemplo: buzón de correo, páginas, portales, \\
aplicaciones, etc.).
\end{tabular}




\begin{tabular}{|c|c|}
\hline $\begin{array}{l}\text { mos (Ej: buzón de correo, páginas, portales, apli- } \\
\text { caciones, etc.). }\end{array}$ & Publicidad \\
\hline $\begin{array}{l}\text { Espiar a los demás, difamar a otros, mentir, utilizar } \\
\text { la tecnología para realizar trampas o hacer daño a } \\
\text { los demás., Robar información, instalar o enviar } \\
\text { software malicioso, secuestrar información. Utili- } \\
\text { zar la tecnología para lucrarse de forma ilícita, ya } \\
\text { sea con menores, adultos o de cualquier otra ma- } \\
\text { nera. Inducir a otros a hacer cosas por moda. }\end{array}$ & Robar \\
\hline $\begin{array}{l}\text { El seguimiento a las actividades cotidianas a tra- } \\
\text { vés de las redes sociales. No es claro y evidente } \\
\text { para la mayoría de los usuarios lo invasivo a la pri- } \\
\text { vacidad de estas aplicaciones. }\end{array}$ & Seguimiento \\
\hline La suplantación de identidades. & Suplantar \\
\hline $\begin{array}{l}\text { Manipular la información para direccionar por ten- } \\
\text { dencia al usuario frente a los competidores. }\end{array}$ & Tendencioso \\
\hline $\begin{array}{l}\text { La manipulación tergiversada de los datos para } \\
\text { conseguir propósitos económicos, acceder a infor- } \\
\text { mación privilegiada sin permiso del dueño de la } \\
\text { misma. }\end{array}$ & Tergiversar \\
\hline $\begin{array}{l}\text { Espiar a los demás, difamar a otros, mentir, utilizar } \\
\text { la tecnología para realizar trampas o hacer daño a } \\
\text { los demás., Robar información, instalar o enviar } \\
\text { software malicioso, secuestrar información. Utili- } \\
\text { zar la tecnología para lucrarse de forma ilícita, ya } \\
\text { sea con menores, adultos o de cualquier otra ma- } \\
\text { nera. Inducir a otros a hacer cosas por moda. }\end{array}$ & Trampear \\
\hline $\begin{array}{l}\text { Dañar a otros por medio de cualquiera de los deli- } \\
\text { tos informáticos, aprovecharse del desconoci- } \\
\text { miento de algunos, violentar la privacidad. Lucrase } \\
\text { ilícitamente. }\end{array}$ & Violentar \\
\hline $\begin{array}{l}\text { No es ético aprovechar la tecnología para vulnerar } \\
\text { los derechos y la privacidad de las personas. }\end{array}$ & Vulnerar \\
\hline
\end{tabular}




\section{Análisis de frecuencias}

\section{El gráfico muestra las estadísticas de los conceptos presentados.}

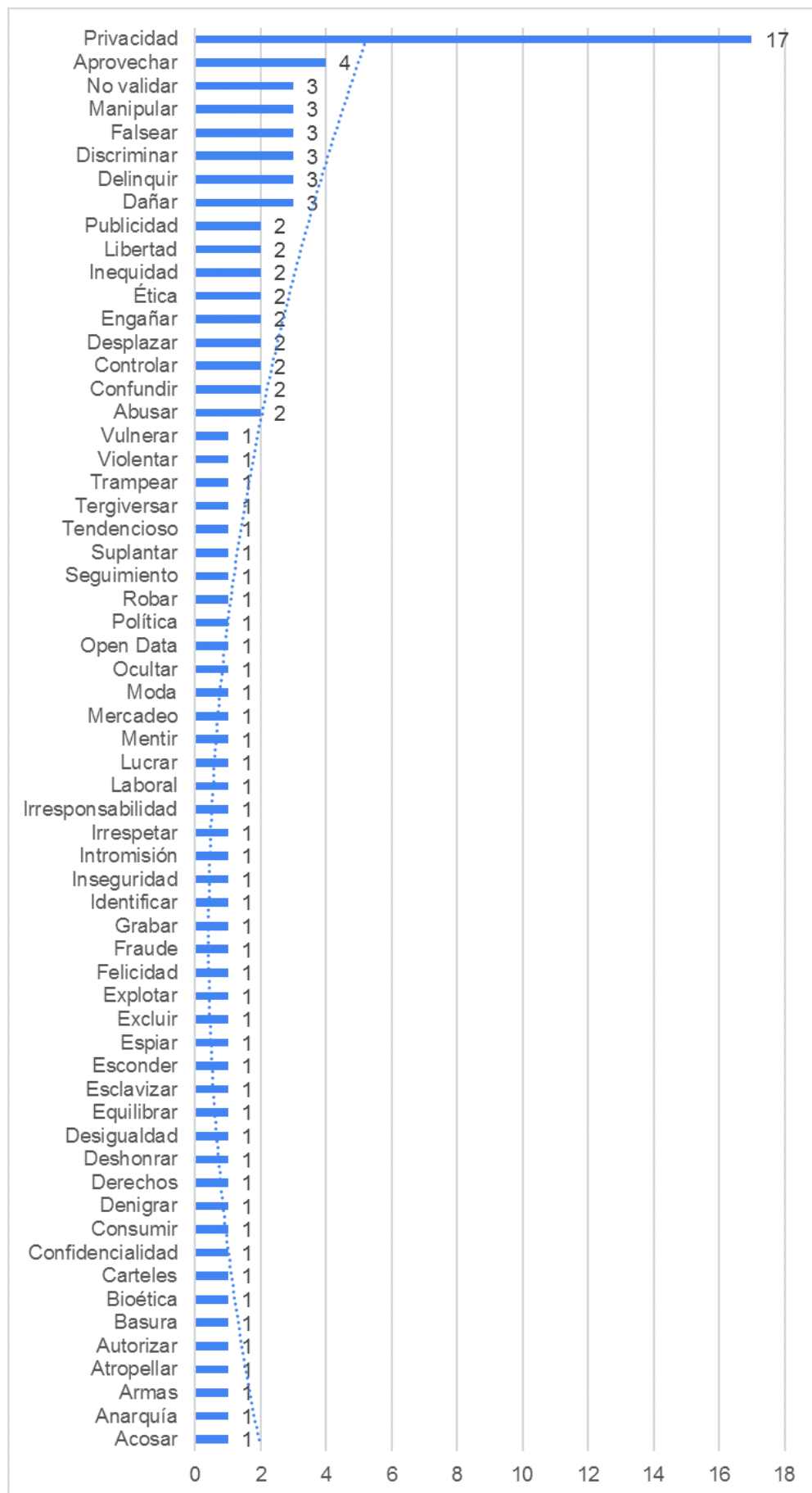

Gráfico 1. Análisis de frecuencia de los términos con los cuales se clasificaron las opiniones. 
Se observa como mayor preocupación que la privacidad de las personas sea vulnerada en redes sociales y otras aplicaciones. Así mismo, la posibilidad de que existan quienes se aprovechen de las personas debido a la facilidad de las comunicaciones en internet. Se considera no ético publicar información basada en datos cuya fuente no haya sido confirmada para considerarla confiable. Dentro de esta misma situación consideran que no es ético manipular los datos para hacerle daño a los demás de manera consciente y planeada.

Adicionalmente, los encuestados consideran que las actividades no éticas con ayuda de las nuevas tecnologías se concentran en las manipulaciones por la publicidad, vulneración de la libertad, inequidad en el ambiente social, discriminación, intentos de engaño, desplazamiento de las personas por las má- quinas, delitos, control de las personas. Se prevén actitudes no éticas dentro del relacionamiento laboral y confusión en las personas, a través de lo que se publica o de los mensajes enviados.

En total fueron 62 clasificaciones sobre posibles actividades no éticas mencionadas por los encuestados.

Taxonomía de la ética debido al uso de tecnologías emergentes

De esta experiencia podemos crear una taxonomía en ética para el uso de las tecnologías emergentes que, aunque contempla solo un grupo encuestado, refleja lo que piensan estos profesionales.

A continuación, se relaciona el significado de los términos utilizados por quienes respondieron la pregunta:

\begin{tabular}{|l|l|}
\hline Términos & Significados bajo el contexto de la ética \\
\hline Acosar & $\begin{array}{l}\text { Perseguir sin tregua ni descanso a una persona } \\
\text { para atraparla. }\end{array}$ \\
\hline Anarquía & $\begin{array}{l}\text { Ausencia total de estructura gubernamental en un } \\
\text { Estado. }\end{array}$ \\
\hline Armas & Uso de las tecnologías para fabricar armas. \\
\hline Atropellar & $\begin{array}{l}\text { Exceso de información para propósitos de diver- } \\
\text { sas índoles. }\end{array}$ \\
\hline Autorizar & Usar información sin permiso. \\
\hline Basura & Información sin calidad. \\
\hline
\end{tabular}




\begin{tabular}{|c|c|}
\hline Bioética & Lo referente a lo "Bios". \\
\hline Carteles & Formación de grupos para manipular mercado. \\
\hline Confidencialidad & $\begin{array}{l}\text { Se refiere al peligro de publicar datos que son se- } \\
\text { cretos. }\end{array}$ \\
\hline Consumir & $\begin{array}{l}\text { Uso de la tecnología para aumentar un consumis- } \\
\text { mo innecesario. }\end{array}$ \\
\hline Denigrar & $\begin{array}{l}\text { Decir cosas negativas en contra del buen nombre, } \\
\text { la fama y el honor de una persona. }\end{array}$ \\
\hline Derechos & Ir en contra de lo que tiene permitido una persona. \\
\hline Deshonrar & Atentar contra la integridad de una persona. \\
\hline Desigualdad & $\begin{array}{l}\text { Manejo de las tecnologías que vaya en contra de } \\
\text { respetar que todos tenemos la misma naturaleza } \\
\text { humana. }\end{array}$ \\
\hline Equilibrar & $\begin{array}{l}\text { Poner a la tecnología con su verdadero valor y no } \\
\text { por encima de las actividades humanas. }\end{array}$ \\
\hline Esclavizar & $\begin{array}{l}\text { Perder el sentido del uso de la tecnología para que } \\
\text { mejore el ser humano y no para que la dependen- } \\
\text { cia de esta sea enfermiza. }\end{array}$ \\
\hline Esconder & Ocultar la verdad es una forma de mentira. \\
\hline Espiar & $\begin{array}{l}\text { Escudriñar a los demás para sacar ventaja usando } \\
\text { las tecnologías. }\end{array}$ \\
\hline Excluir & Dejar por fuera los demás. \\
\hline Explotar & $\begin{array}{l}\text { Los comentarios se orientan a uso excesivo de la } \\
\text { tecnología para control en lo laborar por encima del } \\
\text { respeto a la libertad. }\end{array}$ \\
\hline Felicidad & Hacer infeliz a los demás usando las tecnologías. \\
\hline Fraude & Engaño para ganancias personales. \\
\hline
\end{tabular}




\begin{tabular}{|l|l|}
\hline Grabar & $\begin{array}{l}\text { Utilizar los dispositivos para hacer grabaciones a } \\
\text { escondidas de as personas. }\end{array}$ \\
\hline Identificar & $\begin{array}{l}\text { Confundir la identidad de la persona con la de las } \\
\text { máquinas. }\end{array}$ \\
\hline Inseguridad & $\begin{array}{l}\text { Los riesgos propios de la inseguridad informática y } \\
\text { no esforzarse por mitigarla. }\end{array}$ \\
\hline Intromisión & Entrar a los sistemas ajenos sin permiso. \\
\hline Irrespetar & El mismo sentido del irrespeto en el mundo normal. \\
\hline Irresponsabilidad & $\begin{array}{l}\text { Falta de reflexión en el actuar dentro de las redes y } \\
\text { los sistemas. }\end{array}$ \\
\hline Laboral & $\begin{array}{l}\text { Relativo al trabajo en donde hay un aprovecha- } \\
\text { miento para controlar a los trabajadores. }\end{array}$ \\
\hline Lucrar & $\begin{array}{l}\text { Hacer ganancias inescrupulosas usando las tec- } \\
\text { nologías. }\end{array}$ \\
\hline Mentir & No decir la verdad en las diferentes maneras. \\
\hline Mercadeo & Uso indebido para promover las ventas. \\
\hline Moda & $\begin{array}{l}\text { Usar las tecnologías o promoverlas solo por la mo- } \\
\text { da. }\end{array}$ \\
\hline No mostrar la información con malas intenciones \\
\hline Oadanos
\end{tabular}




\begin{tabular}{|c|c|}
\hline Tendencioso & $\begin{array}{l}\text { Manipular la información para llevar a las personas } \\
\text { a decisiones en contra de su voluntad. }\end{array}$ \\
\hline Tergiversar & $\begin{array}{l}\text { Mostrar la información de manera errada para con- } \\
\text { seguir objetivos. }\end{array}$ \\
\hline Trampear & $\begin{array}{l}\text { Formas diversas de engaño usando las tecnolo- } \\
\text { gías. }\end{array}$ \\
\hline Violentar & Manipular usando procesos a la fuerza. \\
\hline Vulnerar & $\begin{array}{l}\text { Pasar por encima de los derechos de una persona } \\
\text { o institución. }\end{array}$ \\
\hline Abusar & $\begin{array}{l}\text { Hacer uso excesivo o inadecuado de una cosa en } \\
\text { perjuicio propio o ajeno. }\end{array}$ \\
\hline Confundir & $\begin{array}{l}\text { Mostrar información errada para que las personas } \\
\text { entiendan, utilicen o tomen una cosa por otra. }\end{array}$ \\
\hline Controlar & $\begin{array}{l}\text { Dirigir o dominar a una persona o una cosa a través } \\
\text { de los contactos que permite la informática. }\end{array}$ \\
\hline Desplazar & $\begin{array}{l}\text { El reemplazo inadecuado de personas por máqui- } \\
\text { nas. }\end{array}$ \\
\hline Engañar & $\begin{array}{l}\text { Procesos artificiosos para llevar las personas ha- } \\
\text { cia un objetivo. }\end{array}$ \\
\hline Ética & $\begin{array}{l}\text { Los comentarios se refieren a no hablar de ética } \\
\text { como algo no ético. }\end{array}$ \\
\hline Inequidad & $\begin{array}{l}\text { Trato desigual con las personas o empresas de } \\
\text { manera tendenciosa. }\end{array}$ \\
\hline Libertad & $\begin{array}{l}\text { Se refiera vulnerar la libertad de las personas } \\
\text { usandolas tecnologías. }\end{array}$ \\
\hline Publicidad & Publicidad abusiva y tendenciosa. \\
\hline Dañar & $\begin{array}{l}\text { Hacer daño en cualquier forma a las personas o } \\
\text { entidades. }\end{array}$ \\
\hline
\end{tabular}




\begin{tabular}{|l|l|}
\hline Delinquir & Cometer delitos. \\
\hline Discriminar & No contemplar la igualdad entre las personas. \\
\hline Falsear & Disfrazar la verdad. \\
\hline Manipular & $\begin{array}{l}\text { Hacer cambios o alteraciones en una cosa intere- } \\
\text { sadamente para conseguir un fin determinado. }\end{array}$ \\
\hline No validar & $\begin{array}{l}\text { Usar información sin tener seguridad de su origen } \\
\text { verdadero. }\end{array}$ \\
\hline Aprovechar & $\begin{array}{l}\text { Utilizar la información forma consciente solo para } \\
\text { obtener el máximo provecho posible sin pensar en } \\
\text { los demás. }\end{array}$ \\
\hline Privacidad & $\begin{array}{l}\text { Romper o introducirse en lo más profundo de la vi- } \\
\text { da de una persona, que comprende sus sentimien- } \\
\text { tos, vida familiar o relaciones de amistad. }\end{array}$ \\
\hline
\end{tabular}

El comité de ética en la Asociación Colombiana de Ingenieros ACIEM-, trabajando con las Universidades Rosario, Javeriana, Uniminuto, Santo Tomás y la red de los programas de Ingeniería de Sistemas, Industrial, Electrónica, Mecatrónica, Mecánica, Eléctrica, telecomunicaciones, entre otras entidades, dentro de las cuales está la asociación Colombiana de Ingenieros de sistemas -ACIS-, creó los principios éticos de la ingeniería colombiana que se resumen así:

Veracidad. Actuar de conformidad con la verdad, con honestidad y transparencia en la ejecución de nuestros trabajos, en la expresión pública de nuestros conceptos, y siendo agentes dignos de confianza para usuarios, clientes, colegas, compañeros, empleados y/o empleadores.

Integridad. Enarbolar y fortalecer el honor y la dignidad de la Ingeniería, ejerciéndola con integridad profesional, promoviendo las buenas prácticas y el respeto a los demás.

Responsabilidad. Ejercer nuestra actividad atendiendo a las consecuencias de nuestras acciones, dando prioridad a la protección de la vida, la seguridad, la salubridad, el medio ambiente y el cuidado del bien público y fomentando el desarrollo personal y la actualización de los conocimientos, tanto propios como de colegas y terceros.

Precisión. Desarrollar nuestras actividades con precisión y riguro- 
sidad, exclusivamente dentro de los umbrales de nuestra competencia, soportando nuestro desarrollo profesional en el mérito y calidad de nuestros servicios."
El siguiente gráfico refleja el análisis de las prioridades en la actividad ética digital, de acuerdo con los encuestados:

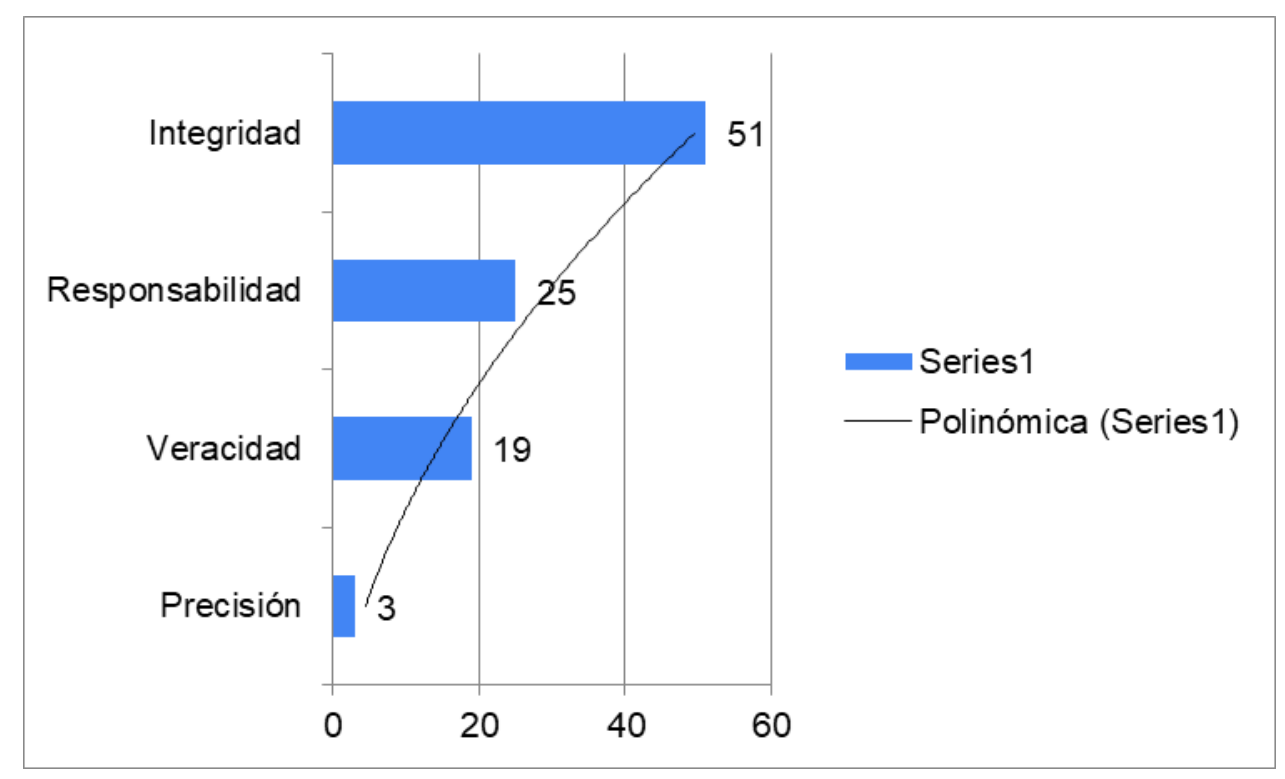

Grafico 2. Análisis de frecuencia bajo los 4 principios de la ética de la ingeniería colombiana

Los resultados muestran que la integridad es el concepto más permeable con relación a actitudes no éticas, lo cual significa que deben predominar las buenas prácticas, en las que el honor y la dignidad deben primar por encima de todo.

Le sigue el principio de la responsabilidad el cual se refiere a la relación con los terceros y con asuntos que pueden comprometer la vida de las personas.

Para esto se sugiere trabajar con buenas prácticas especialmente en lo relacionado con la seguridad informática que cobije el bien general. Debido a que esto requiere conocimientos sólidos en seguridad, la actitud ética para cumplir con esta norma es fundamental.

El principio de veracidad que aparece en tercer lugar es muy afín a las actitudes éticas, porque el sello de la ética se basa en verdad y honestidad. El trato a los demás es considerado también de importancia; en este caso para las personas que rodean al profesional, tanto en lo laboral como en lo personal. 
El cuarto principio considerado susceptible de ser vulnerado fue la precisión, asunto muy pertinente con el desarrollo de la ingeniería.

En el caso del uso de las nuevas tecnologías que controlarán dispositivos, equipos médicos, máquinas industriales y movilidad, todo lo cual se relaciona con la vida de las personas debe cuidarse en gran detalle, puesto que las fallas en la precisión en los algoritmos del soft- ware, por ejemplo, pueden hacer daño a terceros.

Teniendo en cuenta la tendencia de pensar en que las máquinas son el centro en las tecnologías emergentes, se observa una tendencia a centrar la ética en el comportamiento humano puesto que son los profesionales de sistemas quienes las diseñan y programan para que cumplan la tarea para la cual se han diseñado.

Manuel Dávila Sguerra. Director de Ciencias y tecnologías para la vida del Parque científico de innovación social de Uniminuto, Ex decano de la Facultad de Ingeniería de Uniminuto. Ingeniero de Sistemas de la Universidad de Los Andes, Maestría Cum Laude en Filosofía Universidad Javeriana, Columnista de Computerworld, eltiempo.com sobre Linux y el software libre. Tiene 160 artículos publicados y cuatro libros sobre informática. Autor de la plataforma e-Genesis- El Generador de sistemas para la generación automática de software, mención especial en el Premio Colombiano de Informática 2006, miembro fundador de varias asociaciones: Asociación de industriales del software Indusoft, hoy llamada Fedesoft; Asociación Colombiana de Ingenieros de Sistemas-ACIS; gestor y expresidente de la red de Programa de Ingeniería de sistemas, REDIS. 